\title{
Huge Littoral Cell Angioma of the Spleen: A Case Report
}

\author{
Shaocheng Lyu and Qiang He \\ Department of Hepatobiliary Surgery, Beijing Chaoyang Hospital, Capital Medical University, Beijing, China
}

\begin{abstract}
Littoral cell angioma (LCA), a rare vascular neoplasm that occurs in the spleen, is difficult to definitively diagnose preoperatively because histological examination is the only accurate means of diagnosing this condition. Thus, the preoperative diagnosis is often incorrect. Splenectomy is the appropriate treatment and can be performed laparoscopically or by open surgery depending on the size of the tumor. Here we present a case of a 38-year-old man who presented with a history of slight non-specific abdominal distension for 2 months. An abdominal CT scan showed a huge spleen measuring $35 \times 18 \mathrm{~cm}$ and containing multiple lesions, the largest being $11.3 \times 9.2 \mathrm{~cm}$. The patient underwent open splenectomy and recovered well. Histological examination showed LCA of the spleen. To our knowledge, this is the largest reported LCA thus far and may advance our understanding of this condition.
\end{abstract}

(J Nippon Med Sch 2019; 86: 179-182)

Key words: littoral cell angioma, splenectomy, splenic tumor

\section{Introduction}

Littoral cell angioma (LCA) is a rare, idiopathic, benign vascular neoplasm of the spleen ${ }^{1}$ that arises from the cells in the splenic red pulp sinuses ${ }^{2}$. It was first reported and named by Falk et al. in $1991^{3}$. A definitive diagnosis of LCA can only be made by histological examination. Most reports of LCA are of a single case and no more than 200 cases have been reported thus $\mathrm{far}^{4,5}$. Herein we present a patient with a huge splenic LCA, the largest so far reported, who was managed by our team.

\section{Case Report}

\section{Clinical Features and Investigations}

A 38-year-old Chinese man was admitted because of slight non-specific abdominal distension for 2 months. He had experienced no abdominal pain, fever, emesis, anorexia, spontaneous bleeding, or weight loss and had no relevant family or tumor history. Physical examination showed only huge splenomegaly with no other abdominal findings. Laboratory findings included decreased red blood cell $\left(3.87 \times 10^{12} / \mathrm{L}\right)$ and platelet counts $\left(43 \times 10^{9} / \mathrm{L}\right)$. Other blood tests, including tumor markers, liver and renal function, and coagulation were within normal limits. An abdominal CT scan showed a huge spleen measuring
$35 \times 18 \mathrm{~cm}$ and containing multiple lesions, the largest being $11.3 \times 9.2 \mathrm{~cm}$ (Fig. 1). A contrast-enhanced computed tomography (CT) scan revealed peripheral delay enhancement in the venous phase (Fig. 2). A head and chest CT scan were also performed before the operation and showed no metastasis so we did not perform magnetic resonance imaging (MRI) or positron emission tomography (PET)-CT. Finally, our preoperative diagnosis was a splenic malignancy.

\section{Management}

A decision was made to preform a splenectomy. No peritoneal metastases or enlarged lymph nodes were detected intraoperatively. Multiple firm lesions were found in the huge spleen (Fig. 3), which was resected. The operation time was 4 hours and blood loss was $100 \mathrm{~mL}$.

\section{Pathological Findings}

Pathological examination of the operative specimen revealed a huge spleen weighing $2,780 \mathrm{~g}$ and measuring 35 $\times 18 \times 8 \mathrm{~cm}$. The gross pathological examination showed the tumor membrane was smooth and the cut surface was red and white (Fig. 4). Histopathologic examination showed multiple closely packed congested sinusoidal vascular spaces lined with tall endothelial cells (Fig. 5). Immunohistochemistry showed double differentiation of

Correspondence to Qiang He, Department of Hepatobiliary Surgery, Beijing Chaoyang Hospital, Capital Medical University, 8

Gongtinan Road, Chaoyang District, Beijing 100020, China

E-mail: heqiang349@163.com

https://doi.org/10.1272/jnms.JNMS.2019_86-307

Journal Website (http://www2.nms.ac.jp/jnms/) 


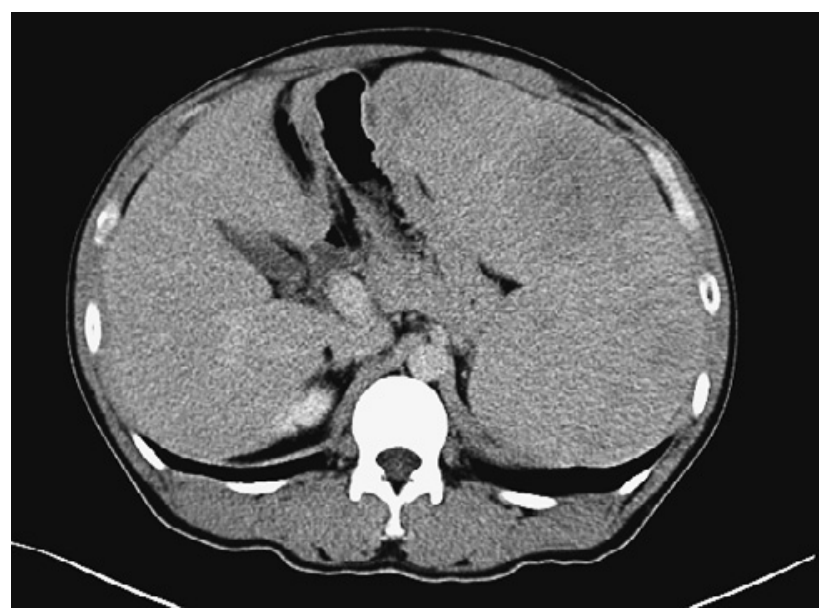

Fig. 1 A CT scan showing huge spleen containing multiple lesions.

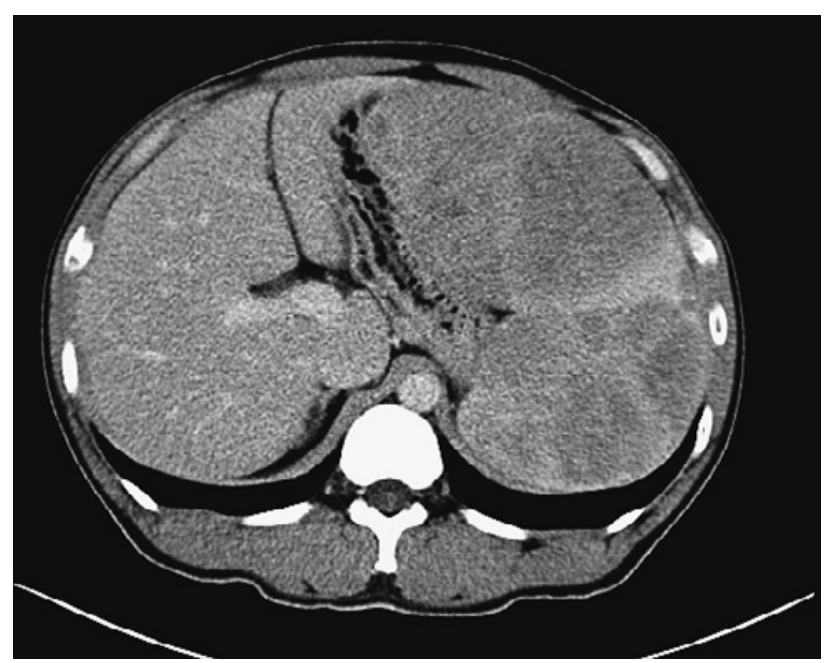

Fig. 2 A contrast-enhanced CT scan showing peripheral delay enhancement.

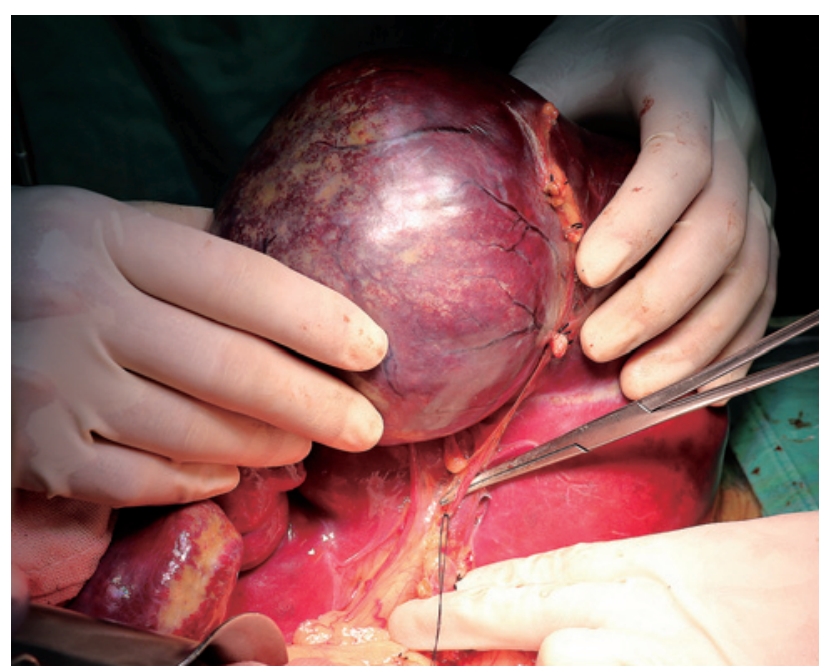

Fig. 3 Multiple firm lesions were found in the huge spleen.

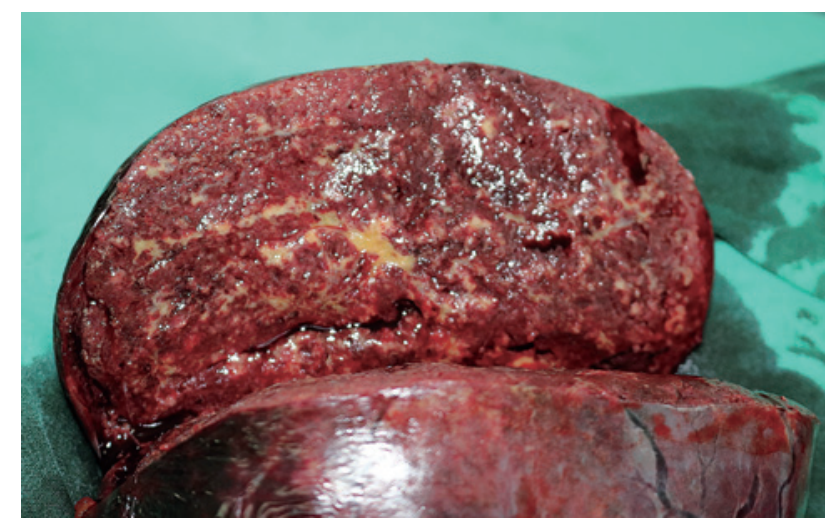

Fig. 4 Gross pathological examination showed the tumor membrane was smooth and the cut surface was red and white.

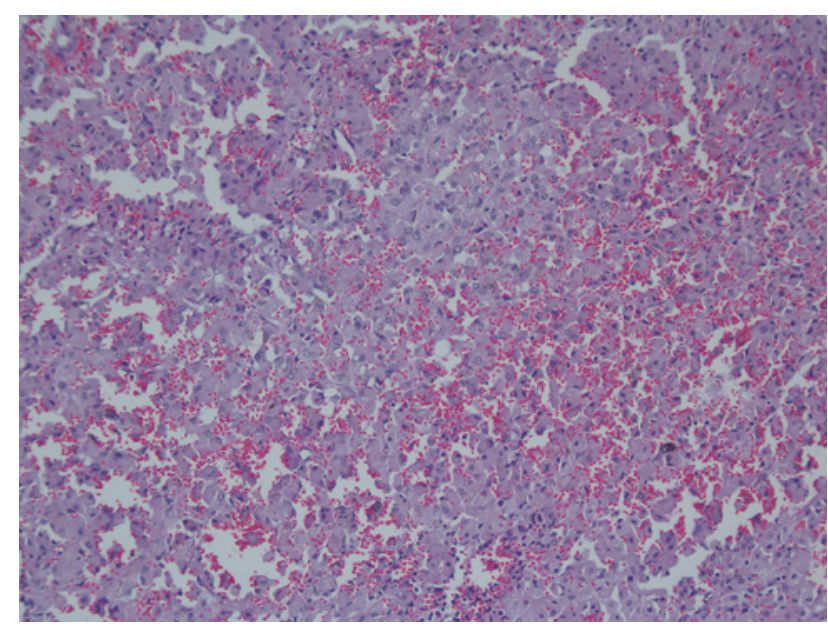

Fig. 5 Multiple closely packed congested sinusoidal vascular spaces lined with tall endothelial cells (hematoxylin-eosin, magnification $\times 100$ ).

endothelial cells (positive for CD31, partially positive for factor VIII, and negative for CD34 and CD8) and histiocytes (positive for CD68 and lysozyme, partially positive for S-100 and CD163, and negative for CD21). The mitotic figures counted 0-1/10HPF and Ki-67 labeling index was no more than $5 \%$. A diagnosis of LCA was therefore made.

\section{Follow-up and Outcomes}

The patient's postoperative course was uneventful. He began to eat on postoperative day two and was discharged on day eight. His red blood cell and platelet counts recovered to normal on day seven. Six months later, he was asymptomatic and an abdominal CT scan showed no abnormalities or recurrence (Fig. 6).

\section{Discussion}

LCA appears to affect men and women equally. The age 


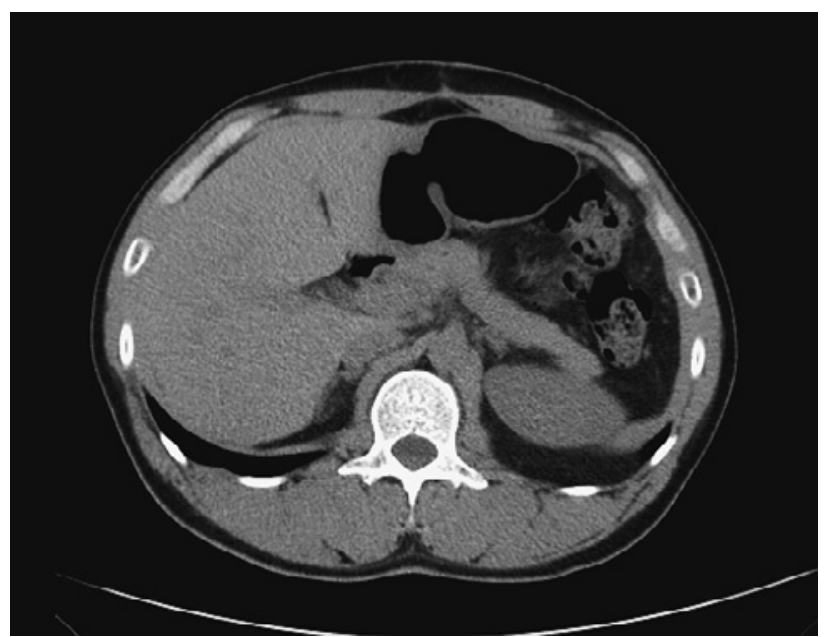

Fig. 6 A CT scan performed 6 months postoperatively showing no abnormality or recurrence.

of patients with LCA ranges from young to old, according to the reports, but most commonly occurs in middleaged adults, the reported age range being 3 to 77 years ${ }^{6}$. Its cause(s) are not yet clear. Some studies suggest it may be caused by cancer or chronic infectious diseases ${ }^{7,8}$. Most patients are asymptomatic; however, some present with abdominal distention, anemia, weakness, or weight loss.

LCA lesions may be multiple or solitary and their diameters range from 1 to $10 \mathrm{~cm}^{9}$. Routine blood tests may suggest hypersplenism and tumor marker concentrations are always normal. Radiological examination shows nonspecific lesions ${ }^{10}$. The differential diagnosis of LCA includes lymphoma, Kaposi sarcoma, and hemangioma ${ }^{11}$. Making a definite diagnosis is challenging because LCA can be diagnosed only on pathological examination. Our patient's spleen was $35 \times 18 \mathrm{~cm}$ in size and the largest lesion was $11.3 \times 9.2 \mathrm{~cm}$, which is the largest reported lesion as far as we know. Our preoperative diagnosis was a splenic malignancy.

The treatment of LCA is laparoscopic or open total splenectomy depending on the size of the spleen ${ }^{10}$. The huge size of our patient's LCA $(35 \times 18 \mathrm{~cm})$, the largest thus far reported, precluded laparoscopic resection. In some cases, partial splenectomy has reportedly been performed with the aim of preserving some splenic function $^{12}$. This was not possible in our patient because of his multiple lesions. The prognosis of LCA is good and there is no need for further therapy postoperatively. However, the patients should undergo close follow-up after splenectomy because $30 \%$ of LCA may be associated with other malignant disease according to the literature ${ }^{13}$. The most common malignancies include lymphoma, colorectal adenocarcinoma, pancreatic carcinoma, renal adeno- carcinoma, gastric leiomyosarcoma, and non-small cell cancer of the lung. In addition, several reports also found LCA had malignancy potential and the most common location of metastasis was the liver ${ }^{14}$. It is not clear how to identify the potential malignancy risk of LCA. It may be related to the mitotic figures and the Ki-67 labeling index according to our literature review. So, a long-term followup for these patients should be recommended, especially for those with atypical histology.

In conclusion, LCA is a rare vascular neoplasm that occurs in the spleen. A definite diagnosis is difficult to make preoperatively because histological examination is the only accurate means of making this diagnosis. The appropriate treatment is splenectomy. Regular postoperative follow-up is recommended. Our patient's lesions were the largest reported thus far. This case report will further understanding of this condition.

Conflict of Interest: There are no conflicts of interest.

\section{References}

1. Johnson C, Goyal M, Kim B, Wasdahl D, Nazinitsky K: Littoral cell angioma. Clin Imaging 2007; 31: 27-31.

2. Gao C, Li YC, Xiao XM, Qi F, Liu T: Littoral cell angioma in the spleen. Br J Hosp Med (Lond) 2015; 76: 55.

3. Falk S, Stutte HJ, Frizzera G: Littoral cell angioma. A novel splenic vascular lesion demonstrating histiocytic differentiation. Am J Surg Pathol 1991; 15: 1023-1033.

4. Anbardar MH, Kumar PV, Forootan HR: Littoral cell angioma of the spleen: cytological findings and review of the literature. J Cytol 2017; 34: 121-124.

5. Kranzfelder M, Bauer M, Richter T, Rudelius M, Huth M, Wagner P, Friess H, Stadler J: Littoral cell angioma and angiosarcoma of the spleen: report of two cases in siblings and review of the literature. J Gastrointest Surg 2012; 16: 863-867.

6. Liu D, Chen Z, Wang T, Zhang B, Zhou H, Li Q: Littoralcell angioma of the spleen: a case report. Cancer Biol Med 2017; 14: 194-195.

7. Bailey A, Vos J, Cardinal J: Littoral cell angioma: a case report. World J Clin Cases 2015; 3: 894-899.

8. Peckova K, Michal M, Hadravsky L, Suster S, Damjanov I, Miesbauerova M, Kazakov DV, Vernerova Z, Michal M: Littoral cell angioma of the spleen: a study of 25 cases with confirmation of frequent association with visceral malignancies. Histopathology 2016; 69: 762-774.

9. Sarandria JJ, Escano M, Kamangar F, Farooqui SO, Montgomery E, Cunningham SC: Littoral cell angioma: gastrointestinal associations. Gastrointest Cancer Res 2014; 7: 63-64.

10. Schneider G, Uder M, Altmeyer K, Bonkhoff H, Gruber M, Kramann B: Littoral cell angioma of the spleen: CT and MR imaging appearance. Eur Radiol 2000; 10: 13951400.

11. Pillay Y, Shokeir MO: Case report of a littoral cell angioma of the spleen and accessory spleens: A benign vascular tumour. Int J Surg Case Rep 2017; 40: 109-112.

12. Marzetti A, Messina F, Prando D, Verza LA, Vacca U, Az- 
abdaftari A, Rubinato L, Reale D, Favat M, Barbujani M, Agresta F: Laparoscopic splenectomy for a littoral cell angioma of the spleen: Case report. World J Clin Cases 2015; 3: 951-955.

13. Maternini M, Misani M, Vanzati A, Romano F, Isimbaldi G, Garancini M, Brenna A, Uggeri F, Uggeri F: Extramedullary hemopoiesis and littoral cell angioma of the spleen: our experience and review. Hepatogastroenterology 2012; 59: 1789-1793.
14. Rosso R, Paulli M, Gianelli U, Boveri E, Stella G, Magrini $\mathrm{U}$ : Littoral cell angiosarcoma of the spleen. case report with immunohistochemical and ultrastructural analysis. Am J Surg Pathol 1995; 19: 1203-1208.

(Received, June 8, 2018)

(Accepted, December 12, 2018) 